Giuliane JeSus Lajos ${ }^{1}$

RENATO PASSINI JUNIOR ${ }^{2}$

MARCelo Luís NOMURA ${ }^{1}$

ELIANA AMARAL ${ }^{2}$

Belmiro Gonçalves Pereira ${ }^{2}$

Helaine Milanez ${ }^{2}$

MARY ÂNGELA PARPINELLI ${ }^{2}$

Artigos originais

Palavras-chave

Trabalho de parto prematuro Ruptura prematura de membranas fetais Complicações infecciosas na gravidez Streptococcus agalactiae

Keywords

Obstetric labor, premature Fetal membranes, premature rupture Pregnancy complications, infectious Streptococcus agalactiae

\section{Colonização bacteriana do canal cervical em gestantes com trabalho de parto prematuro ou ruptura prematura de membranas}

\author{
Cervical bacterial colonization in women with preterm labor or \\ premature rupture of membranes
}

\section{Resumo}

OBJETIVO: estudar a colonização bacteriana do canal cervical em gestantes com trabalho de parto prematuro ou com ruptura prematura de membranas. MÉTODOS: foram avaliadas 212 gestantes com trabalho de parto prematuro ou ruptura prematura de membranas. Na admissão hospitalar foram coletadas duas amostras do conteúdo endocervical e realizadas bacterioscopia e cultura em meios ágar sangue e ágar chocolate. Foram analisadas associações da colonização endocervical com infecção do trato urinário materno, corioamnionite, utilização de antibióticos, sofrimento fetal, prematuridade e infecção e óbito neonatais. RESULTADOS: a prevalência de colonização endocervical foi 14,2\% (IC95\%=9,5-18,9\%), com resultados similares entre os casos com trabalho de parto prematuro ou ruptura prematura de membranas. O microorganismo mais prevalente na população estudada foi o estreptococo do grupo B $(9,4 \%)$, sendo também isolados Candida sp, Streptococcus sp, Streptococcus pneumoniae, Escherichia coli e Enterococcus sp. Das bacterioscopias analisadas, os achados mais freqüentes foram baixa prevalência de bacilos de Döderlein e elevado número de leucócitos. Em mulheres colonizadas, houve maior prevalência de infecção do trato urinário $(23,8$ versus $5,4 \% ; p<0,01)$, infecção neonatal $(25,0$ versus $7,3 \% ; p<0,01)$ e óbito neonatal (dois casos entre as colonizadas; $\mathrm{p}<0,021$, quando comparadas às não colonizadas. CONCLUSÕES: observou-se alta prevalência de colonização endocervical, mesmo sem a utilização de meios de cultura seletivos. $\bigcirc$ estreptococo do grupo B foi o principal microorganismo isolado, reforçando a necessidade de triagem deste agente na gestação. Um terço das culturas positivas ocorreram por outros agentes. Estudos complementares são necessários para esclarecer a importância destes achados bacteriológicos no canal endocervical e sua associação com complicações gestacionais, sepse e mortalidade neonatais.

\section{Abstract}

PURPOSE: to study cervical colonization in women with preterm labor or premature rupture of membranes. METHODS: two hundred and twelve pregnant women with preterm labor or premature rupture of membranes were studied. Two cervical samples from each woman were collected and bacterioscopy and culture were performed. Association of cervical microorganisms and urinary tract infection, chorioamnionitis, fetal stress, antibiotic use, prematurity, neonatal infection, and neonatal death were evaluated. RESULTS: the prevalence of endocervical colonization was $14.2 \%$ $(C \mid 95 \%=9.5-18.9 \%)$, with similar results in preterm labor or premature rupture of membranes. Group B streptococcus was the most prevalent organism (9.4\%). Other organisms isolated were Candida sp, Streptococcus sp, Streptococcus pneumoniae, Escherichia coli and Enterococcus sp. The most common findings of bacterioscopy were a reduced number of lactobacilli and a great number of leukocytes. Endocervical colonization was associated with a higher occurrence of urinary tract infection (23.8 versus $5.4 \%$; $<<0.01$ ), early-onset neonatal infection $(25.0$ versus $7.3 \%$; $\mathrm{p}<0.01$ ) and neonatal mortality (two cases in colonized women; $\mathrm{p}<0.02$ ) when compared with a negative culture of endocervical mucus. CONCLUSIONS: this study showed high prevalence of endocervical colonization despite the use of a nonselective culture media. The main microorganism isolated was group B streptococcus, but other organisms were present in one third of the studied population. More studies are needed to evaluate the influence of endocervical colonization on obstetrical outcome and on neonatal infection and mortality.
Correspondência:

Giuliane Jesus Lajos Rua Alexander Fleming, 101 - Cidade Universitária Zeferino Vaz CEP 13084-881 - Campinas/SP Fone/Fax: (19) 3521-9304 E-mail: giviline@unicamp.br

Recebido

$16 / 6 / 08$
Departamento de Tocoginecologia da Faculdade de Ciências Médicas da Universidade Estadual de Campinas - UNICAMP Campinas (SP), Brasil e Hospital Estadual Sumaré - Sumaré (SP), Brasil.

Médicos do Departamento de Tocoginecologia da Faculdade de Ciências Médicas da Universidade Estadual de Campinas UNICAMP - Campinas (SP), Brasil.

2 Professores-assistentes do Departamento de Tocoginecologia da Faculdade de Ciências Médicas da Universidade Estadual de Campinas - UNICAMP - Campinas (SP), Brasil. 


\section{Introdução}

A flora cérvico-vaginal normal é um dos mecanismos de defesa contra o crescimento e ascensão de patógenos. Os lactobacilos, devido à produção de ácido láctico, peróxido de hidrogênio e outras substâncias antimicrobianas, exercem papel importante nesta defesa local. Na gestação, o desequilíbrio da flora vaginal, principalmente a vaginose bacteriana, favorece colonização por microorganismos associados a complicações da evolução da gestação $0^{1-3}$.

Há evidências de que alterações na flora vaginal levam ao aumento de citocinas (IL-6, IL-8) na região endocervical, sendo estas informações concordantes com a hipótese de infecção ascendente do trato genital inferior, na etiologia do trabalho de parto prematuro (TPP) e da ruptura prematura de membranas ovulares $(\mathrm{RPM})^{4-6}$. Além das citocinas, há mediadores humorais envolvidos na defesa do trato genital inferior, como a imunoglobulina $\mathrm{A}$ ( $\operatorname{Ig} A)$, produzida principalmente na região endocervical. A diminuição cérvico-vaginal da produção de $\operatorname{Ig} A$ está associada à colonização patogênica local ${ }^{7}$.

Embora o mecanismo de quebra da barreira imunológica do trato genital inferior não esteja totalmente esclarecido, a presença de bactérias patogênicas na endocérvice uterina de gestantes está associada à colonização maciça do trato genital inferior e à presença de corioamnionite, ainda que subclínica ${ }^{8,9}$.

Acredita-se que os agentes etiológicos responsáveis pela infecção neonatal grave são originados principalmente de mães com o trato genital inferior colonizado. Há ascensão destes patógenos pela endocérvice, atingindo a decídua, membranas fetais, líquido amniótico e feto ${ }^{6,10}$.

Neste contexto, o microorganismo que tem sido pesquisado é o estreptococo do grupo B (EGB), por sua morbidade e mortalidade neonatais e taxas de colonização materna que chegam até $30 \%{ }^{11,12}$. Além disto, a identificação desta bactéria permite a realização de profilaxia da transmissão vertical, com o uso de antibióticos ${ }^{11,12}$.

Por outro lado, o uso de antibiótico para profilaxia de infecção e sepse neonatal, visando outros microorganismos, tem sido objeto de estudos e ainda é controverso. Nos casos de ruptura prematura de membranas (RPM), há melhora dos resultados materno-fetais com o uso de antibióticos ${ }^{13}$. Porém, em situações de trabalho de parto prematuro (TPP) sem infecção clinicamente detectável ainda não foram evidenciados benefícios ${ }^{14,15}$.

Há uma tendência mundial em buscar a profilaxia da sepse neonatal, por se tratar de doença de instalação e evolução rápidas, podendo levar ao óbito neonatal antes que o diagnóstico etiológico seja estabelecido. Entre as medidas profiláticas neonatais estão o rastreamento de patógenos, no trato genital inferior das gestantes, e o uso de antibióticos pelas mesmas, em algumas situações. Os estudos geralmente focam em apenas um microorganismo, o EGB, sem investigar simultaneamente outros microorganismos ou as interações entre eles. Além do mais, no Brasil, pesquisas nesta linha são raras.

O estudo da colonização endocervical, não somente abordando o EGB, em mulheres com RPM ou TPP, que são fatores de risco para sepse neonatal, pode fornecer resultados de grande utilidade, trazendo informações que faltam na literatura nacional e que podem repercutir no atendimento obstétrico e neonatal.

Este estudo teve como objetivos pesquisar a freqüência e o tipo de colonização endocervical em mulheres com TPP ou RPM e sua associação com resultados perinatais insatisfatórios.

\section{Métodos}

O estudo foi realizado em um hospital secundário vinculado à Universidade Estadual de Campinas (UNICAMP) e localizado na cidade de Sumaré, São Paulo. Foi revisado e aprovado pelo Comitê de Ética em Pesquisa da Faculdade de Ciências Médicas da UNICAMP, sob o processo no $360 / 2003$.

Foram incluídas 212 mulheres com idade gestacional entre 24 e 42 semanas, internadas por TPP ou de RPM, no período de julho de 2002 a janeiro de 2004. Foram critérios de exclusão: cerclagem, malformações uterinas, sangramento vaginal profuso, dilatação cervical completa, bolsa amniótica herniada na vagina, malformações fetais incompatíveis com a vida e óbito fetal. As informações referentes às variáveis estudadas foram coletadas pela revisão dos prontuários médicohospitalares destas pacientes.

Durante o exame ginecológico de admissão hospitalar, foram coletadas duas amostras do conteúdo endocervical. Após a colocação de espéculo estéril, sem lubrificantes, e visualização do colo uterino, foi inserido um swab estéril dentro do canal cervical e realizado movimento rotatório de $360^{\circ}$. Após a retirada do swab, o material obtido foi aplicado em duas lâminas. Da mesma forma foi aplicado um segundo swab, mergulhado em meio de transporte não seletivo $(\mathrm{BHI}=$ brain heart infusion). Este material era levado ao laboratório no prazo máximo de 30 minutos. Com o esfregaço das lâminas, foi realizada bacterioscopia e, com o segundo swab, foi feita cultura em meios ágar sangue e ágar chocolate. A leitura das culturas foi realizada 24 e 48 horas após a semeadura e considerada positiva quando identificados eventuais patógenos.

Foi estimada a prevalência de colonização endocervical destas gestantes e identificados os microorganismos presentes, por meio dos resultados das culturas. 
Outras variáveis maternas analisadas foram: bacterioscopia da secreção endocervical; número de toques antes da admissão e durante o trabalho de parto; infecção do trato urinário (ITU); suspeita de corioamnionite ${ }^{16}$ (definida como alteração de leucograma, taquicardia materna, taquicardia fetal, febre materna e/ou alteração de aspecto/odor do líquido amniótico); uso de antibióticos profiláticos para EGB segundo abordagem por fatores de risco ${ }^{12}$; uso de antibióticos terapêuticos (para tratamento de infecção urinária, intra-amniótica e/ou outras); idade gestacional no parto; via de parto; indicação de cesárea; sofrimento fetal.

As variáveis neonatais avaliadas foram: índice de Apgar de primeiro e quinto minutos, idade gestacional ao nascimento (calculada pelo método de Capurro ou New Ballard), baixo peso de nascimento $(<2.500 \mathrm{~g})$, infecção neonatal precoce e óbito neonatal. As variáveis consideradas dependentes foram comparadas segundo a presença ou ausência de colonização endocervical (variável independente).

Para o cálculo do tamanho amostral, assumiu-se prevalência esperada de colonização endocervical de $25 \%$, ou seja, um exposto (colonizado) para cada três não expostos ${ }^{9}$, incidência esperada de corioamnionite (incluindo as subclínicas) de $20 \%$ entre os expostos e de no máximo $5 \%$ entre os não expostos ${ }^{17}$. Considerou-se erro tipo I e II de 5 e $20 \%$, respectivamente.

$\mathrm{Na}$ análise dos dados foi utilizado o programa Statistical Analysis System (SAS) versão 8.2, estimando-se a prevalência de colonização endocervical, com o respectivo intervalo de confiança (IC) de 95\%. Para as demais variáveis, foram elaboradas tabelas de frequiências e foram aplicados o teste exato de Fisher e teste $\chi^{2}$.

\section{Resultados}

O grupo estudado constituiu-se de 212 gestantes, sendo que $74(35 \%)$ apresentaram diagnóstico inicial de TPP e 138 (65\%) haviam sido internadas por RPM (68 casos de pré-termo e 70 termo). Dentre as mulheres com

Tabela 1 - Características epidemiológicas das mulheres com trabalho de parto prematuro (TPP) ou ruptura prematura de membranas (RPM), segundo o resultado da cultura endocervical

\begin{tabular}{lcccc}
\hline & \multicolumn{5}{c}{ Culfura } \\
\cline { 2 - 5 } Característica & \multicolumn{2}{c}{ Positiva } & \multicolumn{2}{c}{ Negativa } \\
& \multicolumn{2}{c}{ Média } & Média \\
\hline Idade materna (anos) & \multicolumn{2}{c}{23,7} & \multicolumn{2}{c}{23,3} \\
Idade gestacional (semanas) & \multicolumn{2}{c}{35} & \multicolumn{2}{c}{34,2} \\
\hline Paridade $^{*}$ & n & $\%$ & n & $\%$ \\
\hline Primigesta & 10 & 33,3 & 91 & 50 \\
Secundigesta & 11 & 36,7 & 32 & 17,6 \\
3 ou mais gestações & 9 & 30 & 59 & 32,4 \\
\hline
\end{tabular}

*Não significativo; teste exato de Fisher.
RPM pré-termo, 29 (42,6\%) desenvolveram TPP ao longo da internação. A idade gestacional média na internação foi de 34,3 semanas.

Algumas características epidemiológicas da população estudada estão representadas na Tabela 1. Pode-se observar que os grupos com e sem colonização endocervical foram homogêneos, segundo estas características, destacando-se idade materna e gestacional.

Observou-se que a maior parte da amostra procedia das cidades de Sumaré $(57,7 \%)$ e Hortolândia, São Paulo, $(24,5 \%)$. As outras cidades referentes ao Hospital Estadual de Sumaré (HES) contribuíram com 12,5\% dos casos (Nova Odessa, Santa Bárbara d'Oeste e Monte Mor, cidades do Estado de São Paulo) e 5,3\% dos casos vinham de outras regiões. A procedência foi ignorada em quatro casos.

Pouco mais de $1 / 3$ das gestantes tinham sido submetidas ao toque vaginal antes da coleta do material endocervical. Não foi critério de exclusão a presença de toques anteriores, exatamente para se avaliar se isto traria alguma influência nos resultados das culturas. $\mathrm{O}$ antecedente positivo de toque vaginal foi semelhante entre as mulheres colonizadas e as não colonizadas $(35,7$ versus $39,1 \%$, respectivamente). Entre as mulheres com RPM, a mediana do tempo entre a amniorrexe e a internação foi de quatro horas, variando de duas a 216 horas.

A prevalência de colonização endocervical encontrada neste grupo de gestantes foi de 14,2\% (IC95\% $\%$ 9,5-18,9\%). A Tabela 2 mostra a distribuição dos microorganismos encontrados nas culturas, segundo o diagnóstico de internação. Observa-se que o EGB foi o microorganismo mais encontrado (20 casos ou 9,4\%), independente do diagnóstico de internação.

Foi realizado bacterioscopia endocervical em 127 $(59,9 \%)$ das mulheres incluídas no estudo e a Tabela 3 mostra os resultados deste exame, segundo o diagnóstico de internação. Entre os achados microbiológicos considerados alterados, os mais comuns foram bacilos de Döderlein ausentes ou pouco freqüentes (+ em 4+)

Tabela 2 - Distribuição dos resultados da cultura endocervical, segundo o diagnóstico de internação, isto é, trabalho de parto prematuro (TPP), ruptura prematura de membranas pré-termo (RPMPT) e ruptura prematura de membranas a termo (RPMT)

\begin{tabular}{|c|c|c|c|c|c|c|c|c|}
\hline \multirow{3}{*}{ Cultura } & \multicolumn{8}{|c|}{ Diagnóstico de internação } \\
\hline & \multicolumn{2}{|c|}{$\begin{array}{c}\text { TPP } \\
(n=74)\end{array}$} & \multicolumn{2}{|c|}{$\begin{array}{l}\text { RPMPT } \\
(n=68)\end{array}$} & \multicolumn{2}{|c|}{$\begin{array}{l}\text { RPMT } \\
(n=70)\end{array}$} & \multicolumn{2}{|c|}{$\begin{array}{c}\text { Total } \\
(n=212)\end{array}$} \\
\hline & $n$ & $\%$ & $n$ & $\%$ & $n$ & $\%$ & n & $\%$ \\
\hline Strepfococcus agalactiae & 7 & 9,4 & 5 & 7,4 & 8 & 11,5 & 20 & 9,4 \\
\hline Candida sp & 1 & 1,4 & 2 & 2,9 & 2 & 2,8 & 5 & 2,3 \\
\hline Strepfococcus sp & 1 & 1,4 & \multicolumn{2}{|c|}{0} & 1 & 1,4 & 2 & 1 \\
\hline Streptococcus pneumoniae & 1 & 1,4 & \multicolumn{2}{|c|}{0} & \multicolumn{2}{|c|}{0} & 1 & 0,5 \\
\hline Escherichia coli & 1 & 1,4 & \multicolumn{2}{|c|}{0} & \multicolumn{2}{|c|}{0} & 1 & 0,5 \\
\hline Enterococcus sp & \multicolumn{2}{|c|}{0} & \multicolumn{2}{|c|}{0} & 1 & 1,4 & 1 & 0,5 \\
\hline Ausente & 63 & 85,1 & 61 & 89,7 & 58 & 82,9 & 182 & 85,8 \\
\hline
\end{tabular}


Tabela 3 - Distribuição dos achados de bacterioscopia encontrados em mulheres com trabalho de parto prematuro (TPP) ou ruptura prematura de membranas (RPM), segundo o diagnóstico de internação

\begin{tabular}{|c|c|c|c|c|c|c|c|c|}
\hline \multirow[t]{3}{*}{ Achados* } & \multicolumn{8}{|c|}{ Diagnóstico de infernação } \\
\hline & \multicolumn{2}{|c|}{ TPP $(n=47)$} & \multicolumn{2}{|c|}{$\begin{array}{l}\text { RPMPT } \\
(n=41)\end{array}$} & \multicolumn{2}{|c|}{$\begin{array}{c}\text { RPMT } \\
(n=39)\end{array}$} & \multicolumn{2}{|c|}{$\begin{array}{c}\text { Total } \\
(n=127)\end{array}$} \\
\hline & n & $\%$ & n & $\%$ & n & $\%$ & n & $\%$ \\
\hline Döderlein diminuídos & 16 & 34 & 19 & 46,3 & 18 & 46,1 & 53 & 41,7 \\
\hline Leucócitos numerosos & 21 & 44,7 & 15 & 36,6 & 15 & 38,4 & 51 & 40,1 \\
\hline Bacilos difteróides & 5 & 10,6 & 6 & 14,6 & 2 & 5,1 & 13 & 10,2 \\
\hline Leveduras & 3 & 6,4 & 2 & 4,9 & 1 & 2,5 & 6 & 4,7 \\
\hline Normais & 16 & 34 & 17 & 41,4 & 12 & 30,8 & 45 & 35,4 \\
\hline
\end{tabular}

*Algumas mulheres apresentaram mais de uma alteração; RPMPT=ruptura prematura de membranas pré-termo; RPMT = ruptura prematura de membranas a termo.

Tabela 4 - Proporção de mulheres que apresentaram intercorrências durante a gestação, segundo a cultura endocervical

\begin{tabular}{l|ccccc}
\hline Intercorrência & \multicolumn{5}{c}{ Cultura } \\
\cline { 2 - 7 } & \multicolumn{4}{c}{ Positiva } & \multicolumn{2}{c}{ Negativa } & Valor p \\
& n & $\%$ & n & $\%$ & \\
\hline ITU & $5 / 21$ & 23,8 & $7 / 130$ & 5,4 & $<0,01^{*}$ \\
Corioamnionite (suspeita) & $4 / 30$ & 13,3 & $22 / 182$ & 12,1 & NS $^{*}$ \\
Antibiótico terapêutico & $4 / 27$ & 14,8 & $18 / 175$ & 10,3 & NS $^{*}$ \\
\hline
\end{tabular}

*Teste exato de Fisher; ITU=infecção do trato urinário; NS=não significativo; Corioamnionite (suspeita)=alteração de leucograma, taquicardia materna, taquicardia fetal, febre materna e/ou alteração de aspecto/odor de líquido amniótico(16).

Tabela 5 - Proporção de resultados neonatais desfavoráveis, segundo a cultura endocervical

\begin{tabular}{lccccc}
\hline Resultado & \multicolumn{5}{c}{ Culfura } \\
\cline { 2 - 6 } & \multicolumn{4}{c}{ Positiva } & \multicolumn{2}{c}{ Negativa } & Valor $\mathbf{p}$ \\
\hline & $\mathrm{n}$ & $\%$ & $\mathrm{n}$ & $\%$ & \\
Prematuridade & $13 / 28$ & 46,4 & $78 / 172$ & 45,3 & NS \\
Baixo peso $(<2.500 \mathrm{~g})$ & $10 / 29$ & 34,5 & $66 / 176$ & 37,5 & NS \\
Infeccão neonatal & $7 / 28$ & 25 & $13 / 177$ & 7,3 & $<0,01$ \\
Óbito neonatal & $2 / 29$ & 6,9 & $0 / 177$ & 0 & $<0,02$ \\
\hline
\end{tabular}

*Teste $\chi^{2} ; \mathrm{NS}=$ não significativo.

e número de leucócitos aumentado $(++$ em $4+$ ou +++ em 4+). Quando a cultura endocervical era positiva, as alterações de bacterioscopia estavam presentes em $81,3 \%$ dos casos e, quando era negativa, em 62,2\%. Porém, a diferença desta associação não foi significativa. Das gestantes avaliadas, $77(36,3 \%)$ receberam antibiótico para profilaxia de sepse neonatal por EGB ( 49 receberam penicilina cristalina e 28 ampicilina). Entre as que receberam antibioticoprofilaxia, $60(77,9 \%)$ tinham RPM (49 pré-termo e 11 de termo) e apenas $17(22,1 \%)$ tinham diagnóstico de TPP. A proporção de uso de antibiótico profilático foi de $34,5 \%$ entre as colonizadas e $37 \%$ entre as não colonizadas, não havendo diferença entre os dois grupos. As mulheres colonizadas que não receberam profilaxia para EGB tinham, em sua maioria, diagnóstico de
RPM termo, sem fatores de risco para este agente e para uso de antibióticos (12 casos).

Algumas intercorrências durante a gestação foram avaliadas e representadas na Tabela 4 . A única intercorrência materna associada à colonização endocervical foi ITU. A prematuridade, além da colonização endocervical, apresentou associação significativamente maior com ITU (19,1 versus 4,8\%). Observou-se que, nos casos de colonização por EGB, a associação com ITU foi mais freqüente, quando comparado com outros microorganismos ( 28,6 versus $14,3 \%$, respectivamente), porém não houve diferença quanto a este achado.

Dos casos suspeitos de corioamnionite, 15 gestantes apresentavam alteração de leucograma como único achado e quatro tiveram leucograma alterado associado a alguma alteração clínica.

Entre as mulheres incluídas, 206 tiveram seu parto no HES. A média de idade gestacional no parto foi 35,7 semanas, variando de 24 a 43 semanas. Já a mediana do tempo da amniorrexe ao parto foi de 12 horas, com variação de zero a 998 horas. O tempo médio de trabalho de parto foi 4,8 horas, variando de zero a 24 horas. Por fim, a média de toques vaginais durante o trabalho de parto foi de quatro toques, variando entre zero e 13 . Observou-se que $47,6 \%$ das gestantes evoluíram para parto vaginal espontâneo, 21,8\% tiveram parto fórcipe e 30,6\% evoluíram para cesárea. As causas mais freqüentes de cesárea foram distócia (20 casos ou 31,7\%), sofrimento fetal (17 casos ou 27\%), apresentação pélvica (15 casos ou 23,8\%) e iteratividade (sete casos ou 11,1\%). Duas mulheres foram submetidas à cesárea por infecção ovular e não houve associações entre o tipo de parto e o resultado da cultura endocervical. Também não foi observada associação entre a presença de colonização endocervical e sofrimento fetal (6,7\% entre as colonizadas e $7,1 \%$ nas demais).

Ao se avaliarem as características neonatais, observou-se idade gestacional média ao nascimento (Capurro) de 36,5 semanas, variando de 26 a 41 semanas. O peso médio de nascimento foi $2.670 \mathrm{~g}$, variando de $730 \mathrm{a} 4.320 \mathrm{~g}$. Não houve diferenças significativas entre a ocorrência de baixo índice de Apgar $(<7)$ no primeiro minuto $(17,9$ versus $19,3 \%$ ) ou no quinto minuto de vida (zero versus $1,7 \%$ ), segundo a presença ou não de colonização endocervical.

A Tabela 5 mostra alguns resultados neonatais, segundo a positividade da cultura endocervical materna, na qual é possível observar a associação significativa entre colonização endocervical e infecção e óbito neonatal.

Entre as mulheres com cultura endocervical positiva, a infecção neonatal foi significativamente mais freqüente quando a idade gestacional era inferior a 37 semanas, quando comparadas às gestações de termo $(21,4$ versus $3,6 \%$ ). Segundo os microorganismos encontrados nas culturas, observou-se maior ocorrência de infecção neonatal 
nos casos de EGB (33,3 versus $10 \%)$, diferença não significante, pelo número reduzido de casos. Os diagnósticos mais comuns de infecção neonatal foram sepse (14 casos) e pneumonia (dois casos). Dos recém-nascidos com infecção precoce, em apenas um foi identificado o agente, por meio de hemocultura, sendo este microorganismo igual ao da endocérvice (Streptococcus pneumoniae).

Os óbitos neonatais ocorreram em recém-nascidos prematuros, sendo ambos secundários a sepse. Um deles apresentava 24 semanas de idade gestacional e a mãe, cujo diagnóstico de internação era TPP com membranas íntegras, estava colonizada pelo EGB e não recebeu antibiótico profilático. O outro recém-nascido tinha 34 semanas e a mãe foi admitida por TPP com ruptura de membranas havia cinco horas, tendo recebido profilaxia para EGB e colonização por $S$. pneumoniae. Este microorganismo também foi isolado na hemocultura do recém-nascido.

\section{Discussão}

O principal achado deste estudo foi a associação de culturas endocervicais positivas com morbidades infecciosas materno-fetais, como infecção urinária e infecção neonatal, principalmente nos casos de prematuridade.

Inicialmente seria necessário entender o motivo pelo qual apenas algumas gestantes apresentam colonização endocervical e, ainda, por que entre as colonizadas somente algumas evoluem com complicações maternas e neonatais. No entanto, não há estudos que respondam claramente a esta questão. Sabe-se que os microorganismos que colonizam o trato genital inferior, muitas vezes considerados da flora normal, não reconhecidamente patógenos, podem produzir fatores (IgA proteases, neuraminidases, mucinases, fosfolipases) que quebram a barreira cervical e adentram a cavidade amniótica ${ }^{6,18,19}$. Provavelmente, as mulheres mais susceptíveis à infecção do trato genital devem ter os mecanismos de defesa locais fragilizados, incluindo a proteção realizada pela flora normal e aquela feita por citocinas e por mediadores humorais, havendo favorecimento do crescimento e da atuação de microorganismos com potencial patogênico ${ }^{20}$. A ocorrência de quatro vezes mais ITU entre as mulheres colonizadas e o fato de o agente, quando identificado, ser o mesmo na endocérvice e trato urinário sugerem um problema imunológico que favoreceria o crescimento local de patógenos.

Observou-se que a colonização endocervical não é somente uma alteração materna local, podendo levar a repercussões neonatais, uma vez observadas associações significativas com infecção precoce e óbito. Estas observações estão de acordo com dados da literatura e sustentam a hipótese de que os microorganismos patogênicos podem atingir o feto por via ascendente do trato genital inferior ${ }^{2,6,10}$.
Entre os neonatos com infecção precoce, houve pesquisa do agente infeccioso, com realização de hemocultura. Em apenas um caso esta foi positiva ( $S$. pneumoniae, presente também na endocérvice materna). A baixa prevalência de hemoculturas neonatais positivas pode ser justificada pelo uso materno de antibiótico profilático, durante o período periparto. Nestes casos, a cultura endocervical materna poderia auxiliar a equipe de neonatologia, visto que a colonização genital por EGB aumenta significativamente o risco de sepse neonatal precoce por este agente.

A escolha do conteúdo endocervical como objeto de análise se baseou no fato de a endocérvice ser um local de transição entre o meio contaminado vaginal e a cavidade uterina, estéril, e de o muco cervical ser descrito como uma barreira à ascensão de germes para a cavidade uterina. Apesar de não haver descrição na literatura sobre qual é a flora normal da endocérvice, a presença de patógenos no colo uterino está mais estreitamente relacionada à colonização maciça de trato genital inferior materno e, nestas situações, há maior risco de resultados obstétricos desfavoráveis ${ }^{18}$.

A técnica de cultura realizada neste estudo teve limitações quanto à avaliação de bactérias anaeróbias que, sabidamente estão associadas ao TPP, à RPM e a infecções puerperais maternas. Limitou-se também pelo fato de não se fazer pesquisa do EGB em meio seletivo, o que é recomendado para as culturas vaginais e anais, nas quais a população bacteriana é numerosa e variada em espécies. No entanto, provavelmente isso não se aplica à flora cervical ${ }^{12}$.

A opção de realizar as culturas endocervicais em meios não seletivos foi intencional, pois isto facilitaria a implantação desta coleta nas rotinas assistenciais de instituições com menores recursos. Sabe-se que meios de cultura seletivos são mais dispendiosos e não estão disponíveis de modo geral nas maternidades do Brasil e, quando se trata de colonização materna maciça por EGB, este pode ser identificado em meios de cultura convencionais $^{18,21}$. Além disto, o estudo não foi focado apenas na investigação do EGB, mas também para buscar informações sobre a prevalência de outras bactérias e suas possíveis repercussões materno-fetais.

Ao se analisar os resultados das culturas, pôde-se estimar que os meios de cultura utilizados não influenciavam negativamente na avaliação da presença de EGB, principal agente associado a sepse neonatal precoce, uma vez que a prevalência deste foi de $9,4 \%$, resultado compatível com estudos semelhantes ${ }^{22}$. Em um estudo recente, avaliou-se a prevalência de EGB no reto e na vagina de mulheres com TPP e RPM pré-termo utilizando meio seletivo e foi encontrada prevalência de colonização de 25,2\% em TPP e 30\% em RPM pré-termo, porém não foi estudada a taxa de colonização na região cervical ${ }^{23}$. 
Esperava-se encontrar maior porcentagem de casos com colonização por outros microorganismos como, por exemplo, Escherichia coli. Isto não ocorreu, talvez pelo fato de o uso de antibióticos não ter sido critério de exclusão e, em algumas gestantes que já vinham utilizando tratamento para ITU, a presença desta bactéria colonizando a endocérvice poderia estar subestimada. Outra bactéria prevalente em estudos similares, que não foi encontrada na população estudada, foi o Streptococcus aureus. Outros autores, avaliando microorganismos endocervicais em mulheres com RPM pré-termo, encontraram positividade para $E$. coli que variou de 4,8 a $16 \%$ e prevalência de $S$. aureus variando de 15,9 a $32,4 \%{ }^{24,25}$.

Outros microorganismos foram encontrados nas culturas, porém com baixa prevalência e aparentemente sem repercussões clínicas materno-fetais. Apesar de não haver diferenças significativas, as gestantes colonizadas pelo EGB tiveram maior prevalência de ITU e de infecção neonatal, quando comparadas às colonizadas pelos outros microorganismos. Acredita-se que, se houvesse uma casuística maior, talvez estas diferenças fossem significativas. Isto reforça a necessidade de se pesquisar o EGB na gestação e em casos de TPP e RPM.

A ausência de associação entre corioamnionite e presença de colonização patogênica endocervical foi um achado não esperado. Uma das justificativas para isto pode ser o critério utilizado na definição de suspeita de corioamnionite $^{16}$. A maioria das gestantes apresentou, como única característica, alteração do leucograma, revelando assim que apenas este critério talvez não seja um bom indicador da presença de corioamnionite. O melhor método diagnóstico de infecção corioamniótica seria a realização de cultura do líquido amniótico, com avaliação histopatológica complementar da placenta e membranas ${ }^{26,27}$, porém esta investigação não foi feita neste estudo.

$\mathrm{Na}$ endocérvice das gestantes estudadas, observou-se, ainda, baixa prevalência de bacilos de Döderlein e grande quantidade de leucócitos. Isto permite a remissão a um questionamento sobre o papel dos lactobacilos na manutenção do equilíbrio microbiológico na região cervical. Apesar de haver pouca literatura sobre a flora e a celularidade da endocérvice, acredita-se que a presença de lactobacilos no muco cervical assim como na vagina tem efeito protetor sobre a colonização do canal cervical. Svare et al. ${ }^{28}$, estudando a relação entre antecedente de conização cervical, colonização microbiana cervical e ruptura prematura pré-termo de membranas, compararam a flora endocervical de gestantes com TPP, RPM pré-termo e de gestantes sem estas condições (Grupo Controle). Encontraram positividade de 56\% para bacilos de Döderlein, no Grupo Controle, havendo uma redução significativa entre as gestantes com RPM pré-termo (34\%). Este estudo mostrou que a diminuição da população de lactobacilos indica uma mudança de flora endocervical, aumentando o risco de colonização patogênica e suas repercussões. Desta forma, a baixa colonização por lactobacilos, associada à intenso infiltrado leucocitário, detectados pela coloração de Gram do conteúdo endocervical, pode ser considerada um método rápido de detecção de corioamnionite em mulheres com RPM pré-termo ${ }^{8,24}$.

Os autores do presente estudo acreditam que a pesquisa de colonização endocervical em gestantes é recomendável na prática clínica diária, especialmente em situações de risco para corioamnionite e prematuridade, como TPP e RPM pré-termo. Estudos complementares se fazem necessários para definir o papel destes achados bacteriológicos no canal endocervical e suas associações a complicações gestacionais, sepse e mortalidade neonatal.

\section{Referências}

1. Usui R, Ohkuchi A, Matsubara S, Izumi A, Watanabe T, Suzuki $M$, et al. Vaginal lactobacilli and preterm birth. J Perinat Med. 2002;30(6):458-66.

2. Svare JA, Schmidt $H$, Hansen BB, Lose $G$. Bacterial vaginosis in a cohort of Danish pregnant women: prevalence and relationship with preterm delivery, low birthweight and perinatal infections. BJOG. 2006; 113(12):1419-25.

3. Verstraelen $H$, Verhelst R, Roelens K, Claeys G, Weyers S, De Backer $E$, et al. Modified classification of Gram-stained vaginal smears to predict spontaneous preterm birth: a prospective cohort study. Am J Obstet Gynecol. 2007;196(6):528.e1-6.

4. Sakai M, Ishiyama A, Tabata M, Sasaki Y, Yoneda S, Shiozaki $A$, et al. Relationship between cervical mucus interleukin-8 concentrations and vaginal bacteria in pregnancy. Am J Reprod Immunol. 2004;52(2):106-12.
5. Sawada M, Otsuki K, Mitsukawa K, Yakuwa K, Nagatsuka M, Okai T. Cervical inflammatory cytokines and other markers in the cervical mucus of pregnant women with lower genital tract infection. Int J Gynaecol Obstet. 2006;92(2): $117-21$.

6. Romero R, Gotsch F, Pineles B, Kusanovic JP. Inflammation in pregnancy: its roles in reproductive physiology, obstetrical complications, and fetal injury. Nutr Rev. 2007;65(12 Pt 2):S194-202.

7. Glasow S, Stepan H, Sack U, Faber R. Cervical immunoglobulin $A$ and altered vaginal flora in pregnant women with threatened preterm delivery. J Perinat Med. 2004;32(1):37-41.

8. Svare J, Andersen LF, Langhoff-Roos J, Madsen H, Jensen ET, Bruun $B$, et al. Uro-genital microbial colonization and threatening preterm delivery. Acta Obstet Gynecol Scand. 1994;73(6):460-4.

9. Curzik D, Drazancić A, Hrgović Z. Nonspecific aerobic vaginitis and pregnancy. Fetal Diagn Ther. 2001;16(3):187-92. 
10. Romero R, Chaiworapongsa T, Espinoza J. Micronutrients and intrauterine infection, preterm birth and the fetal inflammatory response syndrome. J Nutr. 2003;133(5 Suppl 2):1668S$1673 \mathrm{~S}$

11. Prevention of perinatal group B streptococcal disease: a public health perspective. Centers for Disease Control and Prevention. MMWR Recomm Rep. 1996;45(RR-7):1-24.

12. Schrag S, Gorwitz R, Fultz-Butts K, Schuchat A. Prevention of perinatal group $B$ streptococcal disease. Revised guideline from CDC. MMWR Recomm Rep. 2002;51 (RR-1 1):1-22.

13. Kenyon S, Boulvain M, Neilson J. Antibiotics for preterm rupture of membranes: a systematic review. Obstet Gynecol. 2004;104/5 Pt 1):1051-7.

14. King J, Flenady V. Prophylactic antibiotics for inhibiting preterm labour with intact membranes. Cochrane Database Syst Rev. 2002;(4):CD000246.

15. Ovalle A, Romero R, Gómez R, Martínez MA, Nien JK, Ferrand $P$, et al. Antibiotic administration to patients with preterm labor and intact membranes: is there a beneficial effect in patients with endocervical inflammation? J Matern Fetal Neonatal Med. 2006; 19(8):453-64.

16. Hagberg $H$, Wennerholm U, Sävman K. Sequelae of chorioamnionitis. Curr Opin Infect Dis. 2002;15(3):301-6.

17. Cunningham FG, Gant NF, Leveno KJ, Gilstrap III LC, Hauth JC, Wenstrom KD. Williams obstetrics. 21 st ed. New York: McGrawHill; 2001. p. 689-727.

18. Regan JA, Klebanoff MA, Nugent RP, Eschenbach DA, Blackwelder WC, Lou $Y$, et al. Colonization with group B streptococci in pregnancy and adverse outcome. VIP Study Group. Am J Obstet Gynecol. 1996;174(4):1354-60.

19. Rezeberga D, Lazdane G, Kroica J, Sokolova L, Donders GG. Placental histological inflammation and reproductive tract infections in a low risk pregnant population in Latvia. Acta Obstet Gynecol Scand. 2008;87(3):360-5.

20. Bélec L. [Defenses of the female genital tract against infection]. J Gynecol Obstet Biol Reprod (Paris). 2002;31 (6 Suppl):4S454S59. French.

21. Dunne WM Jr, Holland-Staley CA. Comparison of NNA agar culture and selective broth culture for detection of group $B$ streptococcal colonization in women. J Clin Microbiol. 1998;36(8):2298-300.

22. Hordnes K, Tynning T, Kvam Al, Jonsson R, Haneberg B. Colonization in the rectum and uterine cervix with group $B$ streptococci may induce specific antibody responses in cervical secretions of pregnant women. Infect Immun. 1996;64(5): 1643-52.

23. Nomura ML, Passini Júnior R, Oliveira UM. Selective versus nonselective culture medium for group $B$ streptococcus detection in pregnancies complicated by preterm labor or preterm-premature rupture of membranes. Braz J Infect Dis. 2006;10(4):247-50.

24. Silva MG, Peraçoli JC, Sadatsune T, Abreu ES, Peraçoli MT. Cervical Lactobacillus and leukocyte infiltration in preterm premature rupture of membranes. Int J Gynaecol Obstet. 2003;81 (2):175-82.

25. Ustün C, Koçak I, Bariş S, Uzel A, Saltik F. Subclinical chorioamnionitis as an etiologic factor in preterm deliveries. Int J Gynaecol Obstet. $2001 ; 72(2): 109-15$

26. Zlatnik FJ, Gellhaus TM, Benda JA, Koontz FP, Burmeister LF. Histologic chorioamnionitis, microbial infection, and prematurity. Obstet Gynecol. 1990;76(3 Pt 1):355-9.

27. Heller DS, Rimpel LH, Skurnick JH. Does histologic chorioamnionitis correspond to clinical chorioamnionitis? J Reprod Med. 2008;53(1):25-8.

28. 28. Svare JA, Andersen LF, Langhoff-Roos J, Jensen ET, Bruun B, Lind $\mathrm{I}$, et al. The relationship between prior cervical conization, cervical microbial colonization and preterm premature rupture of the membranes. Eur J Obstet Gynecol Reprod Biol. 1992;47(1):41-5. 